\title{
Effects of Oil/Moisture Changes after Using Herbal Peeling Therapy on Women in their 20s and 30s with Comedonal Acne Skin
}

Suyeun Lim, Ki Han Kwon*

Division of Beauty Arts Care, Department of Practical Arts, Graduate School of Culture and Arts, Dongguk University, Seoul, Korea

\author{
"Corresponding author: Ki Han Kwon, \\ Division of Beauty Arts Care, Department of \\ Practical Arts, Graduate School of Culture \\ and Arts, Dongguk University, 30, Pildong- \\ ro 1-gil, Jung-gu, Seoul 04620 Korea \\ Tel.: +82222603606 \\ Fax: +82 222603741 \\ Email: kihan.kwon@dongguk.edu
}

Received July 30, 2020

Revised November 09, 2020

Accepted November 24, 2020

Published December 30, 2020

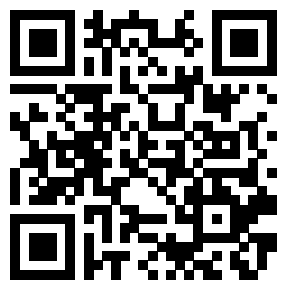

\begin{abstract}
Purpose: Nowadays, modern people are stressed both externally and internally, and as their lifestyle changes, their skin becomes more sensitive. Peeling reportedly results in fundamental improvements on the skin; it compensates for skin defects and makes the skin healthy. It is also used in aesthetics or in the hospital to manage signs of skin aging, such as wrinkles. This study aimed to present useful basic data for improving skin care by comparing and verifying oil and moisture changes. Here, we applied herbal peeling therapy to evaluate its effectiveness and development potential for skin improvement. Methods: This study examined 15 women in their 20 s and 30 s who had comedonal acne on the face to compare the oil and moisture changes to determine the efficacy of the peeling therapy in improving skin condition. Results: After the experiment, groups A and B demonstrated statistically significant increases in oil content $(p=0.0369$ and $p=0.0438$, respectively). However, only group A showed a statistically significant increase in moisture ( $p=0.009$ vs. $p=0.1569$ ). Conclusion: Overall, peeling improved the comedonal acne of the subjects, except for some because of inability to control the side effects due to climate change. We look forward to conducting additional research to provide the beauty service industry with filling management without side effects.
\end{abstract}

Keywords: Herbal peeling therapy, Skin improvement, Acne skin, Skin oil, Skin moisture

\section{Introduction}

현대 사회에서 개인의 image를 표현하는 가장 중요한 요소로 외 모가 우선 순위에 있으며, 피부에 대한 관심도가 남녀노소 할 것 없 이 증가하고 있다(Park \& Lee, 2018). 생활 수준과 경제적 수준 이 높아짐에 따라 보여지는 시선을 중요하게 인식하고 있어 외모관 리 증대를 위해 시간을 아끼지 않고 있으며(Lee \& Choi, 2015), 미 의 대한 표현 기준은 그들만의 니즈에 맞게 다양하게 변화되는 추세 이다(Lee et al., 2014). 또한, 복잡해진 사회 문화 속에서 현대인들 은 외적이나 내적으로 스트레스를 받고 있으며, 그로 인해 생활습관 이 바뀌어가면서 피부는 민감해지고 피부질환이 생겨나고 있다(Lee $\& \mathrm{Kim}, 2010)$. 피부관리 기술의 진화로 인해 대중적 수요가 늘어 (Carraway, 1997), 미용적인 면에서도 표면적인 아름다움보다는 자
연스러움을 강조하면서 피부의 근본적인 개선에 더욱 관심을 보이 며 피부의 결점을 보완하고 건강한 피부상태로 만들어 주는 방법들 이 도입되고 있는데(Kim, 2020), 필링은 그 방법 중 하나로 흥터나 주름 및 피부 노화 등을 개선하기 위해 에스테틱이나 병원에서 사용 되어 왔다(Gold, 2003). 적용의 깊이도에 따라 표층박피, 중층박피, 심층박피로 분류하고, 매개체 사용에 따라 종류가 나뉘어지는데 화 학적, 물리적, 레이저 필링으로 분류가 된다(Kim et al., 2009). 필 링은 피부침투 영역에 따라 약간의 차이가 있지만 콜라겐 합성을 촉 진하여 탄력, 주름 개선 효과와 여드름 개선 등을 목적으로 시행되 고, 대부분 색소성 피부의 미백작용에 효과가 보고되었다(Lee et al., 2005). 여드름의 경우 연령에 상관없이 외부환경적 요인이나 스 트레스로 인해 흔히 발생하고(Lee \& Son, 2018), 심리적으로도 여 러 가지 복합적인 영형을 끼친다(Lee \& Choi, 2019). 피부개선을 통 
해 대인관계에 긍정적인 영향을 미치게 됨으로써 다양한 방법과 지 속적인 관리에 대한 니즈는 더욱 높아지고 있다. 특히, 건강한 피부 는 유분과 수분의 적절한 조화로 인해 정신적인 건강과 외적인 아름 다움을 표출하는데 중요하다(Kim, 2017). 약초 필링의 장점은 부작 용이 거의 없으며, 적용 전 마취할 필요가 없어 자극 받기 전 피부로 의 회복이 빠르며 치료 효과를 빨리 볼 수 있다. 또한, 각질을 주기적 으로 탈락시킴으로 진피의 손상을 최소화하면서 피부재생과 개선에 점진적 효과를 보여줌으로 관리 전반에 있어 광범위하게 이용되고 있고(Kong \& Hwang, 2010), 약초 성분의 미립자로 인해 미네랄 성 분의 흡수율을 높여 피부의 노폐물을 제거해주는 특징이 있다(Han $\& \mathrm{Kim}, 2014)$. 약초 필링의 연구 동향으로는 "약초필링 후 함량이 다른 세라마이드 적용 피부 관리가 홍반과 보습에 미치는 영향(Oh \& $\mathrm{Ahn}, 2013) "$ 밖에 없는 실정이다. 따라서, 본 연구는 좁쌀여드름이 심하게 나타나는 이마 부위에 약초 필링을 적용하여 유분 및 수분 등 의 변화를 비교 검증하고 약초 필링의 유효성과 발전 가능성을 제시 하여 피부 관리 시 개선효과를 높이기 위한 유용한 기초자료로 제시 하는 것을 목적으로 한다.

\section{Methods}

\section{1. 연구대상 및 자료 수집 기간}

본 연구는 약초 필링의 문제성 피부의 효능개선에 대한 차이를 비 교하기 위해 진행하였고, 연구 대상자는 (Kim \& Choi, 2018)와 Kim et al. (2011)의 연구를 참조하여 구성하였다 서울 및 수도권 20-30 대 여성 중 안면 부위에 Comedonal acne를 가지고 있는 15 명을 대 상으로 필링적용군과 필링미적용군, 대조군인 클렌징만 적용한 3 group으로 나누어 연구를 진행하였다. 연구 기간은 2019년 6월 25 일부터 7 월 24 일까지 4 주에 걸쳐서 진행하였다. 연구대상자들에게 연구와 관련된 모든 정보와 취지를 충분히 설명 후 연구대상자는 자 발적 의사에 따라 사전동의서를 작성하고 연구에 참여하였다.

1) 선정기준은 아래와 같다.

(1) 좁쌀여드름을 가진 자

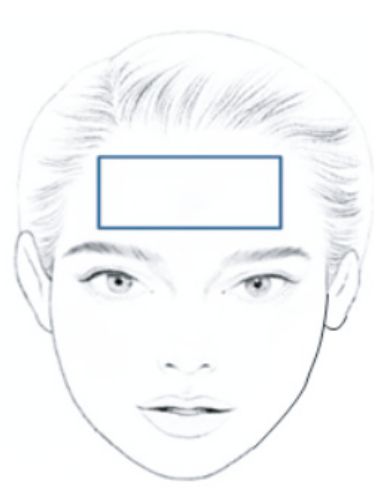

Figure 1. Region of interest area.

(2) 모공의 크기가 넓고, 피지분비량이 많은 자

(3) 피부표면이 울퉁불퉁한 자

(4) 연구기간에 별도의 피부과 및 피부 관리실 등에서 안면관리를 받지 않을 자

(5) 연구의 목적을 숙지하고 연구 참여에 동의한 자

\section{2. 연구방법}

1) 연구재료

클렌징 단계에서는 문제성 피부에 자극이 되지 않도록 $\mathrm{B}$ 사의 젤타 입 클렌징을 이용하였다. 약초가루와 활성제를 이용해 실험을 시행 하였고. Group A는 클렌징, 약초필링, 재생마스크를 모두 적용하였 으며 group B는 클렌징, 재생마스크를 적용하였고 대조군은 클렌징 만 적용하여 실험을 시행하였다. 이와 같이 제품의 적용 실험의 경우 각각의 단독 적용이 실행되어야 하지만, 약초 필링만 단독 적용 할 경우 피부의 예민도가 상승할 수 있으므로 단독효과를 측정하기에는 한계점이 있어 단독 적용군은 추가하지 않았다. 실험에 사용된 제품 의 전 성분은 아래 Table 1 과 같다.

\section{2) 연구도구}

연구대상자들은 본 실험에 대한 목적과 실험 방법에 대한 설명과 정을 충분히 거쳐 사전 동의 하에 설문조사와 피부 측정에 응하였고,

\section{Table 1. Ingredients of cosmetics}

\begin{tabular}{ll}
\hline Type & Aqua, Cocamidopropyl betaine, Coco-glucoside, Alcohol denat., Glycerin, Propanediol, Acrylates/C10- \\
& 30 Alkyl acrylate crosspolymer, Sodium chloride, Pyrus malus fruit Water, Panthenol, Phenoxyethanol, \\
& Caprylyl/Capryl glucoside, Sodium hydroxide, Butylene glycol, Equisetum arvense extract, \\
Ethylhexylglycerin, Sodium benzotriazolyl butylphenol sulfonate, Disodium EDTA, Mentha piperita & Extract, Aloe barbadensis leaf extract, Bioflavonoids, Brassica oleracea italica extract, Pantolactone, \\
& Citric acid, Ci 19140, Ci 42090 \\
Herbal peel powder & Hydrolyzed sponge, Equisetum arvense leaf Extract, Calendula officinalis flower extract, Rosmarinus \\
& officinalis (Rosemary) leaf extract, Spirulina maxima extract, Plantago lanceolate leaf extract \\
& Aqua, Panthenol, Butylene glycol, Aloe barbadensis leaf juice, Chamomillla recutita (Matricaria) flower/ \\
Herbal peel activater & Adenosine, Benzyl Alcohol, Glyceryl caprate
\end{tabular}


사전 설문조사는 생활 습관에 관한 인식도 6 문항으로 구성되었다. 본 연구에서 응답자의 일반적 특성으로 연령, 결혼상태, 피부표면, 직업, 수면시간, 피부관리 경험으로 Nam \& Yi (2017), Lee et al. (1993), Kim et al. (2013), Roditis et al. (2019), Han (2019)의 연 구를 참조하여 구성하였다, 실험 전 동일제품의 클렌징젤(BABOR, Germany)의 적용 후 1 차로 피부 유·수분 측정을 유·수분 측정기 (IC-HSP001; Innoinsight INC, Korea)를 이용하여 측정하였다.

세안 후 약초 필링을 $5 \mathrm{~min}$ 적용한 group $\mathrm{A}(5$ 명), 약초 필링을 비 적용하고 재생마스크만 $5 \mathrm{~min}$. 적용한 group $\mathrm{B}$ (5명), 그리고 클렌 징만 적용한 control group(5명)을 대상으로 하였고 실험 후 홈케어 를 하지 않도록 하였다.

피부관찰은 1 주일 단위로 최소 4 주간 실시하였으며, 실험 후 피 부측정은 실험 전 피부측정과 동일한 도구와 방법으로 측정하였다. 또한, 측정 부위는 좁쌀여드름이 제일 많은 부위인 Figure 1 의 구역 안으로 정하였다.

\section{3) 자료처리 및 분석방법}

본 연구를 위해 실험 결과를 토대로 수집된 자료는 연구에 목적에 따라 SPSS20.0버전(IBM, USA)을 이용하여 분석하였다. 통계분석 방법은 실험 방법 적용에 따른 실험 전후의 평균값 변화분석을 위해 대응표본 $t$-검정을 실시하였다.

\section{Results and Discussion}

\section{1. 일반적 특성}

실험자의 일반적 특성은 Table 2 와 같다. 연령의 경우 20 세 이상 25세 미만이 가장 많아 6 명(40\%), 다음으로 25세 이상 30세 미만, 30 세 이상 35 세 미만 및 35 세 이상 40 세 미만은 각각 3 명 $(20 \%)$ 으로 나타났고, 15 명 $(100 \%)$ 모두 미혼으로만 구성되었다. 피부 표면은 좁쌀여드름 피부가 8명(53.3\%), 화농성여드름 피부가 2명(13.3\%), 화이트, 블랙헤드 피부가 5 명(33.3\%), 직업은 무직이 5 명(33.3\%), 회사원 4명 $(26.6 \%)$, 사업가 3 명 $(20.0 \%)$, 전문직 3 명 $(20.0 \%)$, 수 면시간은 5 시간이 6 명(40.0\%), 6시간이 5명(33.3\%), 7시간이 1명 $(6.67 \%), 8$ 시간 이상이 3 명 $(20.0 \%)$ 이었다. 피부관리 경험은 없다가 2 명(13.3\%), 3달전이 7명(46.6\%), 6개월 전 4명(26.6\%), 1년 전이 2명(13.3\%)로 나타났다.

\section{2. 약초필링 후 안면 피부 개선에 대한 설문조사 분석결과}

약초필링 후 안면 피부 개선에 대한 설문조사 분석 결과는 Table 3 와 같다. 좁쌀여드름의 개선으로는 group $\mathrm{A}$ 는 3 명이 상당히 개선 이 3 명 $(60 \%)$, 약간 개선이 2 명(40\%)으로 나타났다. Group B는 약 간 개선이 5 명 $(100 \%)$ 으로 나타났다. 각질 개선으로는 group A는 약 간 개선이 3 명 $(60 \%)$, 상당히 개선이 2 명 $(40 \%)$ 으로 나타났고, group

Table 2. General features of the test subjects

\begin{tabular}{|c|c|c|c|}
\hline Provision & Variables & Frequency $(\mathrm{N})$ & Percentage (\%) \\
\hline \multirow{4}{*}{ Age } & Over 20-under 25 & 6 & 40.0 \\
\hline & Over 25 -under 30 & 3 & 20.0 \\
\hline & Over 30-under 35 & 3 & 20.0 \\
\hline & Over 35-under 40 & 3 & 20.0 \\
\hline \multirow{2}{*}{ Marital status } & Single/unmarried & 15 & 100.0 \\
\hline & Married & 0 & 0.0 \\
\hline \multirow{3}{*}{ Skin surface } & Comedonal acne & 8 & 53.3 \\
\hline & Pustular acne & 2 & 13.3 \\
\hline & Whitehead, blackhead & 5 & 33.3 \\
\hline \multirow{5}{*}{ Job status } & None (housewife/student included) & 5 & 33.3 \\
\hline & Employee & 4 & 26.6 \\
\hline & Business & 3 & 20.0 \\
\hline & Professional & 3 & 20.0 \\
\hline & Others & 0 & 0.0 \\
\hline \multirow{4}{*}{ Sleep time } & 5 hours & 6 & 40.0 \\
\hline & 6 hours & 5 & 33.3 \\
\hline & 7 hours & 1 & 6.67 \\
\hline & Over 8 hours & 3 & 20.0 \\
\hline \multirow{4}{*}{ Skin care experience } & None & 2 & 13.3 \\
\hline & Before 3 month & 7 & 46.6 \\
\hline & Before 6 month & 4 & 26.6 \\
\hline & Before 1 year & 2 & 13.3 \\
\hline
\end{tabular}


Table 3. Subject's satisfaction after treatment

\begin{tabular}{|c|c|c|c|c|c|c|c|}
\hline \multicolumn{2}{|c|}{ Self-awareness satisfaction } & \multicolumn{2}{|c|}{ Group A } & \multicolumn{2}{|c|}{ Group B } & \multicolumn{2}{|c|}{ Control group } \\
\hline 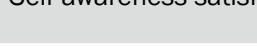 & (10) & $\mathrm{N}$ & $\%$ & $\mathrm{~N}$ & $\%$ & $\mathrm{~N}$ & $\%$ \\
\hline \multirow{5}{*}{$\begin{array}{l}\text { Improvement of } \\
\text { Comedonal acne }\end{array}$} & Worsened significantly & 0 & 0.0 & 0 & 0.0 & 0 & 0.0 \\
\hline & Worsened & 0 & 0.0 & 0 & 0.0 & 0 & 0.0 \\
\hline & Neutral & 0 & 0.0 & 0 & 0.0 & 5 & 100.0 \\
\hline & Improved & 2 & 40.0 & 5 & 100.0 & 0 & 0.0 \\
\hline & Improved significantly & 3 & 60.0 & 0 & 0.0 & 0 & 0.0 \\
\hline \multirow{6}{*}{$\begin{array}{l}\text { Improvement of } \\
\text { exfoliation }\end{array}$} & Worsened significantly & 0 & 0.0 & 0 & 0.0 & 0 & 0.0 \\
\hline & Worsened & 0 & 0.0 & 0 & $0 . .0$ & 0 & 0.0 \\
\hline & Neutral & 0 & 0.0 & 0 & 0.0 & 5 & 100,0 \\
\hline & Improved & 3 & 60.0 & 5 & 100.0 & 0 & 0.0 \\
\hline & Improved significantly & 2 & 40.0 & 0 & 0.0 & 0 & 0.0 \\
\hline & Worsened significantly & 0 & 0.0 & 0 & 0.0 & 0 & 0.0 \\
\hline \multirow{5}{*}{$\begin{array}{l}\text { Improvement of } \\
\text { pigment lesion }\end{array}$} & Worsened & 0 & 0.0 & 0 & 0.0 & 5 & 100.0 \\
\hline & Neutral & 0 & 0.0 & 5 & 100.0 & 0 & 0.0 \\
\hline & Improved & 1 & 20.0 & 0 & 0.0 & 0 & 0.0 \\
\hline & Improved significantly & 4 & 80.0 & 0 & 0.0 & 0 & 0.0 \\
\hline & Worsened significantly & 0 & 0.0 & 0 & 0.0 & 0 & 0.0 \\
\hline \multirow{5}{*}{$\begin{array}{l}\text { Improve skin } \\
\text { moisturization }\end{array}$} & Worsened & 0 & 0.0 & 0 & 0.0 & 0 & 0.0 \\
\hline & Neutral & 0 & 0.0 & 0 & 0.0 & 5 & 100.0 \\
\hline & Improved & 2 & 40.0 & 5 & 100.0 & 0 & 0.0 \\
\hline & Improved significantly & 3 & 60.0 & 0 & 0.0 & 0 & 0.0 \\
\hline & Worsened significantly & 0 & 0.0 & 0 & 0.0 & 0 & 0.0 \\
\hline \multirow{5}{*}{$\begin{array}{l}\text { Improvement of skin } \\
\text { texture }\end{array}$} & Worsened & 0 & 0.0 & 0 & 0.0 & 5 & 100.0 \\
\hline & Neutral & 0 & 0.0 & 0 & 0.0 & 0 & 0.0 \\
\hline & Improved & 0 & 0.0 & 5 & 100.0 & 0 & 0.0 \\
\hline & Improved significantly & 5 & 100.0 & 0 & 0.0 & 0 & 0.0 \\
\hline & Worsened significantly & 0 & 0.0 & 0 & 0.0 & 0 & 0.0 \\
\hline \multirow{4}{*}{$\begin{array}{l}\text { Skin tone or overall } \\
\text { skin improvement }\end{array}$} & Worsened & 0 & 0.0 & 0 & 0.0 & 0 & 0.0 \\
\hline & Neutral & 0 & 0.0 & 1 & 20.0 & 5 & 100.0 \\
\hline & Improved & 2 & 40.0 & 4 & 80.0 & 0 & 0.0 \\
\hline & Improved significantly & 3 & 60.0 & 0 & 0.0 & 0 & 0.0 \\
\hline
\end{tabular}

Table 4. Comparison of individual forehead in terms of oil content for group A

\begin{tabular}{lcccccc}
\hline Group A & Case 1 & Case 2 & Case 3 & Case 4 & Case 5 & Average \\
Pre-experiment (AU) & 47 & 50 & 54 & 62 & 45 & 51.6 \\
Post-experiment (AU) & 58 & 56 & 63 & 71 & 54 & 60.4 \\
Difference (AU) & +11 & +6 & +9 & +9 & +9 & +8.8 \\
\hline
\end{tabular}

Table 5. Comparison of individual forehead in terms of oil content for group B

\begin{tabular}{lcccccc}
\hline Group B & Case 1 & Case 2 & Case 3 & Case 4 & Case 5 & Average \\
Pre-experiment (AU) & 50 & 53 & 49 & 46 & 42 & 48.0 \\
Post-experiment (AU) & 53 & 56 & 53 & 52 & 48 & 52.4 \\
Difference (AU) & +3 & +3 & +4 & +6 & +6 & +4.4 \\
\hline
\end{tabular}


$\mathrm{B}$ 는 약간 개선이 5 명(100\%)으로 나타났다. Group A는 색소병변의 개선사항에서는 상당히 개선이 4 명(80\%), 약간 개선이 1명(20\%)으 로 나타났고, group B는 5명(100\%) 모두 변화가 없었으며, 특이성 은 control group은 5명(100\%) 모두 약간 악화가 되는 양상을 보였 다. 그 외에 피부 보습력 개선에서는 group $\mathrm{A}$ 는 상당히 개선이 3 명 (60\%), 약간 개선이 2명(40\%)으로 나타났고, group B는 5명(100\%) 모두 약간 개선되었다. 피부결 개선을 보면 group $\mathrm{A}$ 는 상당히 개선 이 전체 5 명(100\%)을 차지했고, group B는 약간 개선이 5 명(100\%) 모두에게 나타났다. 또한, control group은 약간 악화가 5명(100\%) 을 나타냈다. 전반적인 만족도를 볼때, group $\mathrm{A}$ 는 상당히 개선이 3 명(60\%)였고, 약간 개선이 2 명(40\%)로 만족도가 높았고, group B는 약간 개선이 4 명(80\%), 변화 없음이 1 명(20\%)로 나타나 관리를 안 받은 control group보다는 좋은 만족도를 보였다.

\section{3. 실험 후 유분량의 변화}

약초 필링 적용 후 안면 피부의 유분도 변화는 Table $4,5,6$ 과 같다. Table 4의 약초 필링를 적용한 group $\mathrm{A}$ 의 유분량의 변화를 보면 대부분이 높은 변화를 보였다. 가장 큰 변화를 보인 경우는 Case 1 이였는데, $58 \mathrm{AU}$ 로 유분량이 높은 증가량을 보였다. Table 5 의 재생 마스크만 적용한 group $\mathrm{B}$ 의 유분량의 변화를 보면 가장 큰 변화를 보인 경우가 Case 4와 Case 5였다. Case 4와 5는 $52 \mathrm{AU}, 48 \mathrm{AU}$ 로 유분량이 증가하였으며 실험 후 두 그룹 모두 유분량의 긍정적 변화 를 보여 두 그룹 모두 유분량 증가에 효과적임을 알 수 있었다. Park $\&$ Lee (2018)의 연구에서 성인 여성에게 물리적 필링인 해초 필링 을 6 주간 적용 후 유분량을 비교한 결과 유의미한 증가를 보여 본
연구 결과와 유사하였다. 이는 본 연구와 적용 부위는 다르지만 물 리적 필링 자체가 주는 각질제거의 효능으로 피지분비가 원활해짐 에 따라 유분량 증가에 영향을 준 것이라 추정된다. 위 결과에 따르 면 개개인으로 보았을 때 유분량의 증가의 폭이 일정하지는 않으나 평균적으로 실험군들이 대체적으로 유분이 증가하는 양상을 보였고 약초 필링을 적용하는 것이 하지 않는 것보다 효과가 더 좋다는 것 으로 해석할 수 있다. 그에 반해 control group은 특별한 변화가 없 었다.

Table 7의 group A, group B, control group 의 각 처치별 유 분량의 변화를 검증한 결과, group $\mathrm{A}$ 의 실험 전/후 변화의 $t$ 값이 -2.0559 로 $p=0.0369$ 로 도출되어 유의수준 0.05 하에 유의한 것으 로 도출되었으며, Group B 또한 $t$ 값 $-1.8367, p=0.0438$ 로 유의수 준 0.05 하에 유의한 것으로 나타났다.

또한 group $\mathrm{A}$ 와 group $\mathrm{B}$ 의 두 그룹 간 실험 후 유분량의 차이에 대한 변화를 검증결과 Table 8에서와 같이 $t=-4.1952, p=0.0030$ 으로 유의수준 0.05 하에 통계적으로 유의한 차이가 있음을 검정하 였다. 이에 실험 후 group $\mathrm{A}$ 의 유분량이 다른 그룹보다 긍정적으로 변화되었다.

\section{4. 실험 후 수분량의 변화}

약초 필링 적용 후 안면 피부의 수분량의 변화는 Table $9,10,11$ 과 같다.

Table 9의 약초 필링을 적용한 group $\mathrm{A}$ 의 수분량의 변화를 보면 가장 큰 변화를 보인 경우가 Case 1과 Case 2였다. Case 1과 2는 $37 \%, 43 \%$ 로 수분량의 긍정적 변화를 보였다. Table 10 의 재생마스

Table 6. Comparison of individual forehead in terms of oil content for control group

\begin{tabular}{lcccccc}
\hline Control group & Case 1 & Case 2 & Case 3 & Case 4 & Case 5 & Average \\
Pre-experiment (AU) & 49 & 42 & 53 & 53 & 54 & 50.2 \\
Post-experiment (AU) & 50 & 43 & 53 & 54 & 53 & 50.6 \\
Difference (AU) & +1 & +1 & 0 & +1 & -1 & +0.4 \\
\hline
\end{tabular}

Table 7. Changes on oil content

\begin{tabular}{|c|c|c|c|c|c|c|c|}
\hline & \multirow{2}{*}{$\mathrm{N}$} & \multicolumn{2}{|c|}{ Pre-experiment } & \multicolumn{2}{|c|}{ Post-experiment } & \multirow{2}{*}{$t$} & \multirow{2}{*}{$p$} \\
\hline & & Mean & $\mathrm{SD}$ & Mean & $\mathrm{SD}$ & & \\
\hline Group A & 5 & 51.6 & 6.7305 & 60.4 & 6.8044 & -2.0559 & $0.0369^{*}$ \\
\hline Group B & 5 & 48.0 & 4.1833 & 52.4 & 2.8809 & -1.8367 & $0.0438^{*}$ \\
\hline Control group & 5 & 50.2 & 4.9699 & 50.6 & 4.5055 & -0.1333 & 0.4486 \\
\hline
\end{tabular}

${ }^{*} p<0.05$; SD, standard deviation.

Table 8. Difference in oil content trend and patterns

\begin{tabular}{|c|c|c|c|c|c|c|c|c|c|}
\hline & \multirow{2}{*}{$\mathrm{N}$} & \multicolumn{2}{|c|}{ Pre-experiment } & \multicolumn{2}{|c|}{ Post-experiment } & \multicolumn{2}{|c|}{ Control group } & \multirow{2}{*}{$t$} & \multirow{2}{*}{$p$} \\
\hline & & Mean & $\mathrm{SD}$ & Mean & $\mathrm{SD}$ & Mean & $\mathrm{SD}$ & & \\
\hline Oil changes & 5 & 8.8 & 1.7888 & 4.4 & 0.8944 & 0.4 & 0.8944 & 4.1952 & $0.0030^{*}$ \\
\hline
\end{tabular}

${ }^{*} p<0.05$; SD, standard deviation. 
크만 적용한 group B의 수분량의 변화를 보면 가장 큰 변화를 보인 경우가 Case 3 와 Case 5 였다. Case 3 와 5 는 $35 \%, 33 \%$ 로 수분량이 증가하였다. Oh \& Ann (2013)의 연구에 의하면 약초 필링을 적용 후 세라마이드를 흡수시켰을 때 수분량의 변화를 확인한 결과, 수분 량 증가에 유의한 영향을 미쳤다고 보고하였다. 그러나 본 연구에서 는 약초 필링만 적용했음에도 수분량이 전체적으로 증가하여, 약초 필링이 수분량에 영향을 미치는 것으로 추정된다. 실험 후 두 그룹 모두 수분량의 긍정적 변화를 보여 두 그룹 모두 수분량 증가에 효 과적임을 알 수 있었다. 위 결과에 따르면 개개인으로 보았을 때 수 분량의 증가의 폭이 일정하지는 않으나 평균적으로 실험군들이 대 체적으로 수분이 증가하는 양상을 보였으므로 약초 필링의 적용이 하지 않는 것보다 효과가 더 좋다는 것으로 해석할 수 있다.

그에 반해 control group은 특별한 변화가 없었다.

Group A, group B, control group의 수분량 변화에 대한 결과
는 Table 12 과 같다. 각 처치별 수분량의 변화를 검증한 결과, 약초 필링을 적용한 group $\mathrm{A}$ 의 경우 실험 전/후 변화의 $t$ 값이 -2.9262 , $p=0.0095$ 로 도출되어 유의수준 0.05 하에 통계적으로 유의한 결 과를 얻었다. Group B의 수분 지수는 실험 전/후 변화의 t값이 $-1.0748, p=0.1569$ 로 통계적으로 유의한 변화는 없었다.

또한, group $\mathrm{A}$ 와 group $\mathrm{B}$ 의 실험 후 수분량의 변화에 대한 차이 는 Table 13에서 보는 바와 같이 $t=-1.9867, p=0.0821$ 로 통계적으 로 유의한 결과를 얻지 못하여 두 그룹 간의 실험 후 수분량의 변화 에는 차이가 없음을 알 수 있었다.

\section{Conclusion}

본 연구는 약초 필링의 적용이 20-30대의 안면피부의 좁쌀여드

Table 9. Comparison of individual forehead in terms of moisture for group A

\begin{tabular}{lcccccc}
\hline Group A & Case 1 & Case 2 & Case 3 & Case 4 & Case 5 & Average \\
Pre-experiment (\%) & 29 & 35 & 40 & 40 & 35 & 35.4 \\
Post-experiment (\%) & 37 & 43 & 45 & 45 & 42 & 42.2 \\
Difference (\%) & +8 & +8 & +5 & +5 & +7 & +8.0 \\
\hline
\end{tabular}

Table 10. Comparison of individual forehead in terms of moisture for group B

\begin{tabular}{lcccccc}
\hline Group B & Case 1 & Case 2 & Case 3 & Case 4 & Case 5 & Average \\
Pre-experiment (\%) & 39 & 42 & 35 & 37 & 35 & 24 \\
Post-experiment (\%) & 42 & 43 & 39 & 39 & 33 & 39.2 \\
Difference (\%) & +3 & +1 & +4 & +2 & +9 & +3.8 \\
\hline
\end{tabular}

Table 11. Comparison of individual forehead in terms of moisture for control group

\begin{tabular}{lcccccc}
\hline Control group & Case 1 & Case 2 & Case 3 & Case 4 & Case 5 & Average \\
Pre-experiment (\%) & 39 & 31 & 36 & 29 & 34 & 33.8 \\
Post-experiment (\%) & 40 & 31 & 35 & 31 & +2 & 34 \\
Difference (\%) & +1 & 0 & -1 & +2 & 0 & +0.4 \\
\hline
\end{tabular}

Table 12. Changes on moisture content

\begin{tabular}{|c|c|c|c|c|c|c|c|}
\hline & \multirow{2}{*}{$\mathrm{N}$} & \multicolumn{2}{|c|}{ Pre-experiment } & \multicolumn{2}{|c|}{ Post-experiment } & \multirow{2}{*}{$t$} & \multirow{2}{*}{$p$} \\
\hline & & Mean & SD & Average & Variance & & \\
\hline Group A & 5 & 35.4 & 6.7305 & 42.2 & 3.1144 & -2.9262 & $0.5009^{*}$ \\
\hline Group B & 5 & 35.4 & 4.1833 & 39.2 & 3.8987 & -1.0748 & 0.1569 \\
\hline Control group & 5 & 33.8 & 4.9699 & 34.2 & 3.7013 & -0.1649 & 0.4363 \\
\hline
\end{tabular}

${ }^{*} p<0.05 ; \mathrm{SD}$, standard deviation.

Table 13. Difference in moisture content trend and patterns

\begin{tabular}{|c|c|c|c|c|c|c|c|c|c|}
\hline & \multirow{2}{*}{$\mathrm{N}$} & \multicolumn{2}{|c|}{ Pre-experiment } & \multicolumn{2}{|c|}{ Post-experiment } & \multicolumn{2}{|c|}{ Control group } & \multirow{2}{*}{$t$} & \multirow{2}{*}{$p$} \\
\hline & & Mean & SD & Mean & SD & Mean & SD & & \\
\hline Moisture changes & 5 & 6.8 & 1.3038 & 3.8 & 3.1144 & 0.4 & 1.1401 & 1.9867 & 0.0821 \\
\hline
\end{tabular}

${ }^{*} p<0.05$; SD, standard deviation. 
름의 개선과 유·수분 변화에 미치는 긍정적 효과를 객관적으로 비 교 검증하여 발전 가능성을 제시하고자 하였다. 연구 대상자는 안 면에 좁쌀여드름이 있는 피부를 가진 20 대-30대의 여성 15 명을 대 상으로 실험 전 설문조사를 통해 연구대상자의 일반적인 특성을 분 석하였고, 4 주에 걸쳐 약초 필링을 적용하였다. 세 그룹 모두 실험 전 동일한 조건과 방법으로 클렌징 적용 후 피부 분석기를 사용하여 유-수분을 측정하여 수치 검정을 하였고 약초 필링 적용 실험을 한 뒤 유분량과 수분량의 값을 비교하여 검증하였다. 그 후 피부의 만 족도 조사를 실시하였고, 그 결과는 다음과 같다.

첫째, 실험 후 유분량의 증가에 대한 변화를 알아보고자 한 결과 는 약초 필링을 적용한 group $\mathrm{A}$ 는 $p=0.0369\left({ }^{*} p<0.05\right)$, 재생마스 크만 적용한 group $\mathrm{B}$ 는 $p=0.0438$ ( $\left.{ }^{*} p<0.05\right)$ 이므로 두 집단 모두 유 분량의 증가가 통계적으로 유의하였고, group $\mathrm{A}$ 는 실험전보다 실험 후 유분량이 증가하였다. 둘째, 실험 후 group A와 group B의 두 그 룹 간 유분량의 변화에 대한 차이를 알아보고자 한 결과는 약초 필 링을 적용한 group $\mathrm{A}$ 의 안면의 유분량의 변화가 통계적으로 유의한 결과 $p=0.003\left({ }^{*} p<0.05\right)$ 을 얻어 약초 필링 적용군이 유분량 증가에 유의함이 검증되었다. 이로써, 유분 발란스를 맞춰 주는데 효과적임 을 알 수 있었다. 셋째, 실험 후 수분량의 증가에 대한 변화를 알아 보고자 한 결과는 약초 필링 적용군 group $\mathrm{A}$ 는 $p=0.0095$ ( $\left.{ }^{*} p<0.05\right)$ 로 통계적으로 유의한 결과를 도출하였고, 재생마스크를 적용한 group $\mathrm{B}$ 는 통계적으로 유의한 결과 $p=0.1569\left({ }^{*} p<0.05\right)$ 를 얻지 못 했지만 두 집단 모두 수분량이 증가하였고, group $\mathrm{A}$ 는 실험전보다 실험 후 수분량이 증가하였다. 넷째, 실험 후 group A와 group B 의 두 그룹 간 수분량의 변화에 대한 차이를 알아보고자 한 결과는 group A와 group B의 안면의 수분량의 변화가 통계적으로 유의한 결과 $p=0.0821\left(^{*} p<0.05\right)$ 를 얻지 못하여 group $\mathrm{A}$ 와 group B의 수 분량의 변화에 있어 차이가 없었다. 수분의 특성은 계절적인 영향으 로 인해 변동성이 크지만 마스크를 착용하는 시대적 상황과 향후 4 계절 변화에 적절히 융화될 수 있게 계절적 통제요인의 한계점을 극 복 해야 할 것이다. 특히 냉난방으로 인한 기온과 습도 변화는 피부 유형에도 영향을 준다(Kwon et al., 2020). 따라서, 이러한 결과로 인해 약초 필링이 효능에서 검증되었고 이로써, 좁쌀여드름 피부에 효과적임을 알 수 있었다. 이와 같은 결과를 통해 약초 필링이 안면 피부의 유분량과 수분량의 변화에 대한 효능을 검증함으로써 여드 름 피부의 효용성 가치에 높은 기대를 할 수 있었다. 좁쌀 여드름은 피부의 유·수분 발란스가 깨지면서 생기는 질환이기 때문에 적절 한 제품과 세안 방법이 중요하다. 하지만, 최근 Covid-19로 인해 대 부분의 사람들이 마스크를 장시간 착용하고 활동을 하고 있어 마스 크 내부의 습기로 인해 관리가 힘든 것이 사실이다. 약초 필링은 각 질제거, 색소병변의 개선, 피부보습의 효과가 뛰어남과 동시에 피부 의 진정효과까지 있는 이상적인 여드름 유효성분의 처리로 인하여 피부에 자극을 가하지 않으면서 유·수분 발란스를 맞춰주어 안면의 좁쌀여드름 피부를 효과적으로 관리할 수 있다는 기초 데이터를 분
석하였기에 본 연구 자료가 향후 지속적인 연구를 통해 피부 미용 산업에서 더욱 다양하게 사용되기를 기대하는 동시에 앞으로 추후 연구에서는 다양한 필링제를 세분화하여 적용시 안면의 상태 변화 에 대한 추가검증이 필요하며, 필링 후 유·수분량과 같은 기초적인 자료를 함께 종합적으로 추가적인 연구를 다각도로 시행 볼 것을 제 언한다.

\section{Author's contribution}

SL did research design, performed experiments, data collection and analysis, and wrote overall papers, and KHK did advisory. All authors read and approved the final manuscript.

\section{Author details}

Suyeun Lim (Graduate student), Division of Beauty Arts Care, Department of Practical Arts, Graduate School of Culture and Arts, Dongguk University, 30, Pildong-ro 1-gil, Jung-gu, Seoul 04620 Korea; Ki Han Kwon (Professor), Division of Beauty Arts Care, Department of Practical Arts, Graduate School of Culture and Arts, Dongguk University, 30, Pildong-ro 1-gil, Jung-gu, Seoul 04620 Korea.

\section{References}

Carraway JH. The skin and its contents. Aesthetic Surgery Journal, 17: 316-317, 1997.

Gold AH. Skin resurfacing techniques. Aesthetic Surgery Journal, 23: 140-141, 2003.

Han DS, Kim HJ. Efficacy analysis of peeling types, the application of peeling in accordance with skin types or conditions and review of follow-up management. Asian Journal of Beauty and Cosmetology, 12: 25-31, 2014.

$\mathrm{Han} \mathrm{HH}$. The relationship among smartphone addiction, lack of sleep and sleeping hours of university students. Journal of Convergence for Information Technology, 9: 213-219, 2019.

Kong HK, Hwang IC. Evaluation of skin moisture, sebum, and skin elasticity in dry and oily skin types after glycolic acid peel. Asian Journal of Beauty and Cosmetology, 8: 1-10, 2010.

Kwon OS, Kang HJ, Han SM, Yoon JS, Cho WH, Oh JY, Lim JM, Song YS, Park SG. Study on the classification and improvement of dehydrated skin under warm air heating 
condition. Journal of the Society of Cosmetic Scientists of Korea, 46: 179-184, 2020.

Kim DM, Kim MS, Jeon YS, Lee SK. The effects of amino fruit acid peeling and diamond peeling on the skin of women in their thirties. Asian Journal of Beauty and Cosmetology, 9: 1-9, 2011.

Kim HK. Skin improvement effects of chemical peeling using lactic acid and glycolic acid, and physical peeling using diamonds and crystals. Journal of the Korea AcademiaIndustrial cooperation Society, 21: 487-497, 2020.

Kim HS, Choi YH. Comparative study on changes in skin condition according to peeling care techniques. Asian Journal of Beauty and Cosmetology, 16: 82-92. 2018.

Kim KS, Hwang SY, Bae SY, Kim BS. A study of the development of oriental herbal cosmetics for young women in their 20 s through the measurement of facial skin conditions and subjective questionnaire survey. Journal of Haehwa Medicine, 21: 105-112, 2013.

Kim MS. A study on the effects of depression caused by skin condition on life stress and quality of life. Journal of the Korean Society of Cosmetology, 23: 739-752, 2017.

Kim YK, Jang KJ, Li SH, An SK, Choe TB. The effect of microneedle therapy system and alpha hydroxy acid peeling on the pores and the hyperpigmentation on men's skin. Asian Journal of Beauty and Cosmetology, 7: 69-79, 2009.

Lee $\mathrm{CH}$, Choi BS. Improvement of facial acne on skin with 3\% spicule. Asian Journal of Beauty and Cosmetology, 17: 397-410, 2019.

Lee GC, Lee JH, Choi YM, Park HJ. Neuropsychiatric aspects of the patients with seborrheic dermatitis. Journal of the Korean Neuropsychiatric Association, 32: 500-506, 1993.

Lee GY, Kim JD. A study on impacts of stress upon female skin color and moisture. Journal of the Korean Society of
Cosmetology, 16: 811-822, 2010.

Lee $\mathrm{HJ}$, Lee CW, Ahn KS, Yun YP, Pyo HB, Cho CH, Hong KY, Hong JT. The effects and mechanisms of glycolic acid on the UV-induced skin cell proliferation. Journal of the Society of Cosmetic Scientists of Korea, 31: 219-226, 2005.

Lee JE, Choi EY. A study on the state of medical skincare and satisfaction level. The Korean Society of Cosmetics and Cosmetology, 5: 73-87, 2015.

Lee JY, Son HJ. Trends in the efficacy and safety of ingredients in acne skin treatments. Asian Journal of Beauty and Cosmetology, 16: 449-463, 2018.

Lee NJ, Cho HB, Yoon HS. The facial skin care effects of the cosmetics which were manufactured with defined cell culture medium 4 after glycolic acid peeling. Asian Journal of Beauty and Cosmetology, 12: 755-763, 2014.

Lee SI. Contemporary beauty expressions from the perspective of lao-tzu's philosophy: focusing on cosmetics advertisement. Journal of Fashion Business, 18: 15-24, 2014.

Nam SI, Yi HJ. Employment status, job stress and depression among medical social workers. Journal of Korean Social Welfare Administration, 19: 77-102, 2017.

Oh SE, Ahn HS. The effect of applying various amounts of ceramide skincare on erythema and moisturizing after herbal peeling. Asian Journal of Beauty and Cosmetology, 11: 305-314, 2013.

Park SY, Lee JN. The effect of glycolic acid peeling and seaweed peeling on keratosis pilaris. Journal of Korea Academi-Industrial Cooperation Societys, 19: 492-504, 2018.

Roditis K, Samara E, Louis K. A survey to assess job satisfaction among junior doctors in Greece. Scientific Chronicles, 24: 72-96, 2019. 


\section{약초필링을 이용한 좁쌀여드름 관리가 20-30대 여성의 유·수분 변화에 미치는 영향}

임수연, 권기한

동국대학교 문화예술대학원 실용예술학과 뷰티아트케어전공, 서울, 한국

목적: 복잡한 사회문화 속에서 현대인들은 외부와 내적으로 스트레스를 받으며 생활방식이 바뀌면서 피부가 민감해지고 피부질환 이 발생하고 있다. 피부 근본적인 개선과 피부 결함을 보완하고 건강한 피부 상태를 만들기 위해 필링이 도입되고 있는데, 그 방법 중 하나로 흥터, 주름, 피부 노화를 개선하는 데 피부관리실이나 병원에서 사용되어 왔다. 약초 필링의 효과와 발전 가능성을 제시 함으로써 유·수분의 변화를 비교·검증해 피부관리 개선에 유용한 기초자료를 제시하는 것을 목적으로 한다. 방법: 본 연구는 약초 필링 적용시 문제성 피부의 효능에 대한 차이를 비교하기 위해 진행하였고, 연구 대상자는 서울 및 수도권 20-30대 여성 중 안면 부위에 comedonal acne를 가지고 있는 15 명을 대상으로 약초 필링을 적용하여 나타나는 효능으로 유·수분의 가치를 비교 하는 연 구를 진행하였다. 결과: 실험 후 유분량의 증가에 대한 변화에서는 group A가 $p=0.0369$ ( ${ }^{*} p\langle 0.05)$, group $\mathrm{B}$ 가 $\mathrm{p}=0.0438$ ( ${ }^{*} p\langle 0.05)$ 이므로 두 집단 모두 유분량의 증가가 통계적으로 유의하게 나타나 두 그룹 모두 실험 후 유분량이 유의적으로 증가하였다. 또 한, 실험 후 두 그룹 간 유분량의 변화에 대한 차이를 알아보고자 한 결과 $p=0.0030$ ( ${ }^{*}\langle 0.05)$ 로 통계적으로 유의하여 $\operatorname{group~} \mathrm{A}$ 와 group B의 유분량의 변화에 있어 통계적으로 유의한 차이가 있음을 검정하였다. 실험 후 수분량의 변화를 알아보고자 한 결과에서 는 group $\mathrm{A}$ 는 $p=0.0095$ ( $p<0.05$ )로 도출되어 통계적으로 유의한 결과를 얻었다. group $\mathrm{B}$ 의 경우 $p=0.1569$ 로 도출되어 통계적으 로 유의한 변화는 없었다. 마지막으로 실험 후 두 그룹 간 수분량의 변화에 대한 차이를 알아보고자 한 결과 $p=0.0821$ 로 통계적으 로 유의하지 못하여 group $\mathrm{A}$ 와 group $\mathrm{B}$ 의 수분량의 변화에는 차이가 없었다. 결론: 약초 필링은 피부개선에 긍정적인 결과를 주었 지만 마스크 착용이나 기후변화 등으로 부작용을 완전히 조절하지 못해 긍정적인 결과를 얻지 못한 경우도 있었다. 향후 연구의 한 계를 보완하는 추가 실험을 통해 피부미용 산업에서 더욱 다양하게 사용되기를 기대하는 동시에 앞으로 추후 연구에서는 다양한 필 링제를 세분화하여 적용시 피부상태 변화에 대한 조사가 이루어져야 할 것을 기대한다.

핵심어: 약초필링, 피부개선, 여드름피부, 유분, 수분

\section{참고문헌}

공희경, 황인철. 글리콜산 필링후 건성 및 지성 피부의 유분, 수분과 피부 탄력도 평가. 아시안뷰티화장품학술지, 8 : $1-10,2010$.

권오선, 강현종, 한승민, 윤지선, 조웅희, 오주영, 임준만, 송영숙, 박선규. 온풍 조건에서 수분 탈락 정도에 따른 피부 분 류 및 개선 방안에 대한 연구. 대한화장품학회지, 46:179-184, 2020.

김경신, 황석연, 배선영, 김병수. 안면 피부 측정 및 주관적 설문 평가를 통한 20 대 여성을 위한 한방화장품 개선 연구. 혜 화의학회지, 21: $105-112,2013$.

김동미, 김미성, 전연숙, 이시경. 아미노 필링과 다이아몬드 필링이 30 대여성 피부에 미치는 영향. 아시안뷰티학술지, 9 : 1-9, 2011.

김미성. 피부 상태에 따른 우울감이 생활 스트레스와 삶의 질에 미치는 영향 비교. 한국미용학회지, 23: 739-752, 2017. 김연경, 장경자, 리순화, 안성관, 최태부. 미세 다륜침(MTS)과 AHA필링이 남성피부의 모공과 색소침착에 미치는 영향. 아시안뷰티화장품학술지, 7: 69-79, 2009.

김현경. 젖산과 글리콜산을 이용한 화학적 필링, 물리적 필링(다이아몬드 필링과 크리스탈 필링)에 따른 피부개선 효과. 한 국산학기술학회논문지, 21: 487-497, 2020.

김희숙, 최영희. 박피 방법에 따른 피부 상태 변화에 관한 비교 연구. 아시안뷰티화장품학술지, 16: 82-92. 2018. 
남석인, 이희정, 고용형태에 따른 직무스트레스와 우울의 관계: 의료사회복지사를 중심으로. 한국사회복지행정학, 19:77-102, 2017.

박서연, 이재남. 글릭콜릭산 필링과 해초 필링이 모공각화증 피부에 미치는 영향. 한국산학기술학회논문지, 19: 492$504,2018$.

오성은, 안홍석. 약초필링 후 함량이 다른 세라마이드 적용 피부관리가 홍반과 보습에 미치는 영향. 아시안뷰티화장품학술 지, 11: 305-314, 2013.

이기철, 이정호, 최영민, 박향준. 지루성피부염의 신경정신과적 측면. 신경정신의학, $32: 500-506,1993$.

이길영, 김주덕. 스트레스가 여성의 피부색과 피부 수분에 미치는 영향. 한국화장품미용학회지, 16:811-822, 2010.

이남지, 조홍범, 윤현수. 글리콜릭산 필링 후 확정세포배양액 4 로 제조한 화장품의 안면피부 미용효과. 아시안뷰티화장품학 술지, 12: 755-763, 2014.

이수인. 현대 미인에 나타난 노자적 미학의 표현양상: 화장품 광고를 중심으로. 패션비지니스, 18:15-24, 2014.

이정은, 최은영. 메디컬 스킨케어의 실태 및 만족도에 관한 연구. 한국화장품미용학회지, 5: 73-87, 2015.

이주연, 손효정. 여드름 피부에 효능 및 안전성을 가진 성분의 연구동향. 아시안뷰티화장품학술지, 16: 449-463, 2018. 이창아, 최배석. $3 \%$ 스피큘을 함유한 세안제의 피부안면 여드름 개선효과. 아시안뷰티화장품학술지, 17: 397-410, 2019. 이화정, 이충우, 안광수, 윤여표, 표형배, 조찬휘, 홍기영, 홍진태. UV에 대한 Glycolic Acid의 피부세포증식 기전연구 및 억제효과. 대한화장품학회지, 31: 219-226, 2005.

한도숙, 김현희. 필링의 종류에 따른 효능분석과 피부유형이나 상태에 따른 필링의 적용 및 사후관리에 관한 고찰. 아시안 뷰티화장품학술지, 12: 25-31, 2014.

한현희. 대학생의 스마트폰중독, 수면부족, 수면시간과의 관계. 융합정보논문지, 9: 213-219, 2019. 


\section{中文摘要}

\section{草本去角皮疗法对20多岁和30多岁女性粉刺痤疮皮肤的油/水分变化的影响}

林秀奸，權起漢”

东国大学文化艺术大学院实用艺术学科美容艺术护理专业，首尔，韩国

目的: 如今，现代人在内部和外部都受到压力，随着生活方式的改变，他们的皮肤变得更加敏感。据报道，脱皮 可以使皮肤得到根本改善。它可以弥补皮肤缺陷，使皮肤健康。它也可用于美学或医院，以管理皮肤衰老的迹 象, 例如皱纹。这项研究旨在提供有用的基本数据, 以通过比较和验证油和水分的变化来改善皮肤护理。在这 里, 我们应用草药去皮疗法来评估其功效和改善皮肤的发展潜力。方法: 本研究检查了20多岁和30多岁的15名 脸上有粉刺痤疮的女性, 比较其油脂含量和水分变化, 以确定脱皮疗法改善皮肤状况的功效。结果: 实验后, $\mathrm{A}$ 组和 $B$ 组的油含量均有统计学上的显着增加（分别为 $p=0.0369$ 和 $p=0.0438 ） 。$ 但是, 只有 $A$ 组显示出统计学上显 着的水分增加 $(p=0.009$ 和 $p=0.1569)$ 。结论: 总的来说, 脱皮改善了受试者的粉刺痤疮, 除了一些原因, 因为 无法控制气候变化带来的副作用。我们期待进行更多的研究，以为美容服务行业提供无副作用的填充管理。

关键词: 草药脱皮疗法, 皮肤改善, 痤疮皮肤, 皮肤油, 皮肤水分 
